\title{
Collaborative video blended learning for exercising higher-order thinking - evaluation using community of inquiry framework
}

\author{
Etsuko Toyoda \\ The University of Melbourne, \\ Parkville, Victoria, 3010, Australia \\ Email: etsuko@unimelb.edu.au
}

\begin{abstract}
This paper presents findings from an examination of different learning experiences in students engaged in intercultural learning activities in a collaborative blended learning environment using video sharing, within a university foreign language course. Learning experience in the video collaborative blended learning environment was evaluated using community of inquiry framework, focusing on cognitive presence in students with different cultural backgrounds. It was hypothesised that multicultural experience would enhance cognitive presence, as profound life experience could fuel higher-order thinking. The results of an in-depth analysis of diaries kept by six students (two international students, two local students with Asian background, and two local students with a relatively monocultural background) indicated that while prior intercultural experience of individual students plays a key role, both teaching presence and social presence also affect the exercise of higher-order thinking.
\end{abstract}

Keywords: community of inquiry; CoI; collaborative; video; blended learning; higher-order thinking; intercultural learning; learning experience; social media; interactive; learning environment; cognitive presence; social presence; teaching presence; foreign language.

Reference to this paper should be made as follows: Toyoda, E. (2015) 'Collaborative video blended learning for exercising higher-order thinking evaluation using community of inquiry framework', Int. J. Social Media and Interactive Learning Environments, Vol. 3, No. 2, pp.126-141.

Biographical notes: Etsuko Toyoda is a Lecturer in the Japanese Programme, Asia Institute, The University of Melbourne. She holds a PhD in Applied Linguistics from The University of Melbourne. She has taught Japanese from beginners to advanced in many leading universities in Asia and Australia. Her research interests include Japanese language and culture, e-learning, computer assisted learning, intercultural learning and learner autonomy. She has published numerous articles in double-peer-reviewed indexed international journals. 


\section{Introduction}

In the past, foreign language teachers taught the target language so that learners would be able to communicate with native speakers who live in the countries where the language is spoken. Teachers also taught the target culture so that learners would know how to behave when interacting with native speakers. Nowadays, however, we need to be aware that learners will probably use the language to communicate with culturally diverse people, where it happens that the common language of communication is that particular language. In such an intercultural communication setting, learners need to know that people communicate through a frame of reference of their cumulative experience within the boundary of their own language(s) and culture(s) (Scarino, 2009). In order to communicate effectively and appropriately with people of different backgrounds, learners need to be equipped with the knowledge, awareness and skills required for intercultural communication (Deardorff, 2006). There is much debate about what attributes are required for intercultural competence. Foreign language ability per se is crucial for intercultural competence (Byram, 2008; Crozet et al., 1999; Scarino, 2009). In addition, one needs to have some knowledge and awareness of the values and beliefs of others and of self, and particularly, higher-order thinking skills to reflect, relate, interpret, analyse, and evaluate (Deardorff, 2006; Gopal, 2011; Laal and Laal, 2012; Lee et al., 2012; Sheets, 2009). To this end, foreign language teachers need to aim at developing, not only language and culture competence, but higher-order skills, all being part of intercultural competence. Higher-order thinking skills are essential requirements, not only for academia, but also for many workplace environments (Casner-Lotto, 2006), into which the majority of students will enter.

Extensive reviews in approaches and methodologies for improving intercultural competence point to collaborative learning and blended-learning. Collaborative learning is "an educational approach to teaching and learning that involves groups of learners working together to solve a problem, complete a task, or create a product" [Laal and Laal, (2012), p.491]. Collaborative learning activities are claimed to be ideal for intercultural learning, and the outcomes multiply if students form heterogeneous groups (Zhang, 2012). One practical application is implementation of activities that are intended to encourage collaboration between students with different backgrounds. Teachers can create an environment where students cannot avoid talking to other students from different backgrounds, for instance, by assigning the creation of a product, which involves discussing controversial global issues, to a group comprising members from various cultures (Toyoda and Chia, 2013). A core requirement for successful collaborative learning is open academic communication, such as exchanges of researched information and considered opinions, between learners, which leads to collaborative construction of knowledge. In addition, for higher-order thinking to be exercised, there is a need for a quiet reflection, during which learners can synthesise and analyse the information and opinions obtained from discussions.

The benefits of collaborative learning could be maximised by the use of blended learning, an integration of face-to-face and online learning experiences (Garrison and Kanuka, 2004; Guzzo et al., 2012; Hinkelman and Gruba, 2012). Technology-based activities allow learners to be connected to a community of learners without being time, place or situation bound (Garrison and Kanuka, 2004). While the term 'blended learning' could refer to various mixes of online and offline learning, the term blended learning in 
this paper refers to "a thoughtful integration of classroom face-to-face learning experiences with online learning experiences" [Garrison and Kanuka, (2004), p.96] for maximising collaborative learning. For the online side of blended learning, Web 2.0 (social media and social networking), such as YouTube, has been receiving attention as an effective tool for developing higher-order thinking skills (Artello, 2014). YouTube is a video sharing site with a social networking function. By incorporating research and discussion components, collaborative project work, for example, creating video clips using YouTube, can encourage students to exercise higher-order thinking skills (Artello, 2014). Creating content of a video clip in a small group also enhances students' social interaction skills (Artello, 2014; Burke and Snyder, 2008).

In the current study, a video collaborative blended learning environment was constructed and evaluated using community of inquiry framework (hereafter $\mathrm{CoI}$ ), which assumes that effective higher-order learning requires a community of inquiry (see Swan et al., 2009 for details). This framework, evolved from social constructivist perspectives (e.g., Vygotsky, 1978), is often used to develop and evaluate learning in blended learning environments (Daspit and D'souza, 2012; Swan et al., 2009). CoI consists of three elements: cognitive presence, social presence, and teaching presence, which mutually support and improve a learning environment as a whole (Garrison et al., 2000). The three presences are defined and described as follows (Garrison and Vaughan, 2008; Swan et al., 2009):

- Cognitive presence: the extent to which learners are able to construct and confirm meaning through sustained reflection and discourse. The meaning construction progresses in four stages: triggering event (identify some issue), exploration (explore issue), integration (construct meaning) and resolution (apply the new knowledge). Cognitive presence is a foundation of CoI that keeps students' focus on academic interests.

- Social presence: the degree to which learners feel connected one to another. CoI emphasises the importance of interactions with other people. Group cohesion, collaboration, openness of communication, and affective/personal connections are crucial aspects of social presence.

- Teaching presence: [the degree to which learners can perceive] the design, facilitation and direction of cognitive and social processes for the purpose of realising personally meaningful and educationally worthwhile learning outcomes. Teachers should be capable of designing and organising a course, including designing curriculum, materials, methods, and timetable, organising online and offline activities, and providing assessments and feedback. Teachers should facilitate online and offline discourses, and stimulate student engagement and interaction. They should also provide scholarly leadership, and offer subject-matter expertise.

This paper examines CoI's cognitive presence in students who participated in a video collaborative blended intercultural learning environment in a Japanese language course at an Australian university, and discusses their cognitive presence in relation to their social and teaching presences. A large volume of research investigating the relationships between the three presences point to strong correlations of social and teaching presences with cognitive presence (see Swan et al., 2009 for review). On the other hand, intercultural learning models and theories suggest that the degree of intercultural learning, which requires higher-order thinking skills, varies due to prior life experiences 
(e.g., Deardorff, 2006; Lee et al., 2012). When students experience a similar amount of social and teaching presences, what makes a difference in their cognitive presence may be individual students' prior life experiences. It is envisaged that learners would more likely to be able to construct and confirm meaning through sustained reflection and discourse if they had plenty of food for thought and ingredients for exchange of opinions. The research question therefore is: in an intercultural learning environment, do students with richer multicultural experience exercise higher-order thinking, and construct and confirm meaning through sustained reflection and discourse, more than do those with less experience?

\section{Learning environment}

Intercultural activities in an advanced Japanese course at an Australian university were designed using CoI as a model. The course comprised two semesters each of 12 weeks, having four face-to-face contact hours per week.

- In order to improve teaching presence, comprehensive intercultural activities were designed as follows:

1 Lecture (face-to-face/online): students gained background knowledge of issues arising in Japanese language and society due to globalisation) via lecture slides and videos.

2 Homework (online): students read reading material using online translation tools, and completed vocabulary/grammar and reading-comprehension tasks to learn linguistic items useful for discussions.

3 Seminar 1 (face-to-face): students compared reading comprehension answers with group members. The teacher guided students for accurate comprehension and appropriate interpretation, and provided further background information.

4 Homework (online): students conducted topic-related research with the purpose of understanding that issues evolving in Japan are not confined to the country, but are part of global phenomena.

5 Seminar 2 (face-to-face): students engaged in discussions following guided questions. The teacher facilitated students to exchange opinions about the topic. Occasionally, Japanese native speakers joined the discussion as visitor participants.

6 Video project (face-to-face/online): across two semesters beyond classroom-based activities, students, in a small group, created six video clips discussing their research and opinions. They then uploaded their videos to YouTube (in an unlisted space) and link them to Facebook to allow students in Japan to watch and comment. Students also submitted self-reflective diaries discussing their activities and experiences. The purposes of this video project were:

a to gain cultural knowledge and awareness of Japan and other countries, by doing research and having discussions with group members having different backgrounds

b to interact with people who live in the country where the language is spoken 
c to acquire not only linguistic and cultural knowledge, awareness and skills, but also higher-order thinking skills.

Regular formative assessments were given to students for their videos and diaries.

- In order to improve social presence: students had interactions with the teacher, group members, other classmates, and students at Japanese universities. Groups comprised students with different backgrounds (e.g., international, local, monolingual/monocultural, multilingual/multicultural, etc.). In semester 1 , the teacher assembled groups according to student backgrounds. Groups stayed unchanged for the whole semester, working together on the four videos. In the second semester, students formed groups on their own under the condition that the members must come from different backgrounds, and groups again stayed unchanged for the two videos. Group members worked together in reading comprehension discussion (seminar 1), and also communicated via Facebook discussion on their video project. Students also exchanged opinions with other classmates in seminar 2 during general discussion. The teacher assisted students to overcome shyness and contribute to discussion, and ensured an environment in which students felt safe to share their experiences. International collaboration involved university students in Japan. The main correspondents were eight students enrolled in a postgraduate course in applied linguistics focusing on second/foreign language acquisition. Further nine volunteer students from three other Japanese universities participated, three of who visited Australia meeting the Australian students during the course. Students were told to be an ambassador of intercultural relation by telling their Japanese counterparts, via videos, their knowledge, opinions and feelings. In return, the Japanese participants posted feedback on language and content of the videos, and also posed some questions, to which the Australian students replied. This international collaboration conducted asynchronously because of the limited timetable overlap.

- In order to improve cognitive presence: students were exposed to issues evolving in Japan due to globalisation via lectures and online readings (triggering event). The students then exchanged opinions with the teacher and with classmates of different cultural backgrounds, and conducted further investigations pertaining to the topics (exploration). As a group, the students shared and integrated their information during the making of videos (integration), following which, students individually wrote diaries reflecting on their learning (resolution). The required cognitive level for engaging in these activities was gradually lifted as time progressed. In semester 1, the students learnt about the changes occurring in languages and language education due to globalisation, which were familiar issues, and the reading materials used were relatively simple and easy to comprehend. The students discussed the issues by sharing related personal experiences, and sought further information via personal websites and online blogs. In the videos, they discussed their experiences with statistical evidence supporting their opinions. In semester 2, the students encountered more serious global issues, such as international migration, inequity, prejudice and discrimination, and nationality and identity. Towards the end of semester 2, they conducted research using scholarly articles, and presented their findings and critical opinions in the videos. 


\section{Data}

In the advanced Japanese course, 35 of 52 undergraduate students who enrolled at the beginning, continued into the second semester (11 international students from the Asian region, 12 local students with an Asian background, 12 local students with a relatively monocultural background). For this study, data of these 35 students initially became the target of analysis. This paper reports the analysis on data from six of these students. These six students were chosen:

a because they came from different cultural backgrounds: two Australian students with a fairly monocultural upbringing (Mike and Rob), two international students relatively new to Australia (Shu and Mei), and two students with multicultural and multilingual life experiences (Joy and Lisa)

b because the two students within each category exhibited distinct learning experiences (i.e., not as a representative sample).

All the six students expressed satisfaction towards the intercultural learning environment. However, close examination of the data indicates their learning experiences varied considerably. The students' background information is shown in Table 1.

Table 1 Background information of participants

\begin{tabular}{|c|c|c|c|c|}
\hline $\begin{array}{l}\text { Name } \\
\text { (pseudonym) }\end{array}$ & Status & $\begin{array}{l}\text { Languages (in the } \\
\text { order of proficiency) }\end{array}$ & Parents' languages & Education \\
\hline Mike & Local - mono & English, Japanese & English & Australia \\
\hline Rob & Local - mono & $\begin{array}{l}\text { English, Japanese, } \\
\text { Italian }\end{array}$ & English & Australia \\
\hline Shu & International & $\begin{array}{l}\text { Mandarin, English, } \\
\text { Japanese }\end{array}$ & Mandarin & China \\
\hline Mei & International & $\begin{array}{c}\text { Mandarin, Cantonese, } \\
\text { Shanhainese, English, } \\
\text { Japanese }\end{array}$ & Mandarin & China \\
\hline Joy & Local - multi & $\begin{array}{l}\text { English, Mandarin, } \\
\text { Cantonese, Hokken, } \\
\text { Japanese }\end{array}$ & $\begin{array}{l}\text { Cantonese, Hokken } \\
\text { (Mandarin) }\end{array}$ & Australia \\
\hline Lisa & Local - multi & $\begin{array}{c}\text { English, Gaelic, } \\
\text { Japanese, Vietnamese }\end{array}$ & $\begin{array}{l}\text { Gaelic, Vietnamese } \\
\text { (English) }\end{array}$ & Australia \\
\hline
\end{tabular}

Data comprised reflective diaries written by the students, self-evaluation surveys of student interactions, and teacher's notes of miscellaneous phenomena. The data were analysed using the grounded theory approach (see Lincoln and Guba, 1985) focusing on the cognitive presence. The reflective diary entries and self-evaluation survey results are the manifestation of inherently cognitive activities. However, due to the interwoven relationship of the teaching, social and cognitive presences (Xin, 2012), the data provided valuable information about students' learning experiences, demonstrating not only the cognitive presence, but also teaching and social presences. Due to the reflective nature, the data are biased towards cognitive and perceived social presences. However, the cognitive and perceived social presences are, in fact, the results of perceived teaching presence. In the following section, the students' learning experiences will be illustrated 
rather holistically, without applying the coding schemes to the analyses of teaching, social and cognitive presences as separate and distinct aspects.

\section{Learning experiences}

\subsection{Mike (local-mono)}

Initially Mike seemed to be a passive member who waited for others' initiatives. However, with the support of group members, he showed increasing willingness to work. In his first group, none of the members led; all listened to each other, and cooperated well to accomplish the tasks. Mike reported, "I'm really happy that our group works well together and supports each other. We all look at each other's work and try to make sure our video flows", and "reading others' scripts and editing my script after getting feedback from my group helped to improve my Japanese". Overall, he expressed joy at working with group members, as follows:

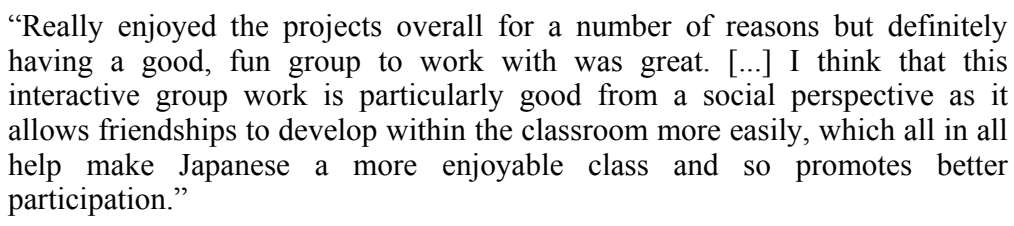

In his semester 2 group, he was again fortunate with his group members. After the first meeting, he expressed, "I'm happy with the group so far, everyone is super keen, really creative, and motivated to work on the video which is nice". All group members seemed to be diligent, which Mike described as "I'm quite impressed at how organised the rest of my group are", and because of the good work habits of the other members, Mike was encouraged to be organised, as expressed in this comment, "on my part perhaps need to be a bit more punctual with keeping up".

This second group worked more collaboratively than his first group. One very organised member "started to write up a small script and uploaded it to Google Drive so we could all access and edit the group script." Mike claimed, "this method of collaboration was really effective as we could all see when each other had put in new parts of their relevant scripts and we could also help each other by reviewing each other's work". Mike summarised his reflection as follows:
"I think working in a group and being able to raise your ideas in a group setting and see each other's Japanese, you tend to pick up and learn a few expressions or words that you didn't already know which is a great complement to the normal learning method. Definitely in our group we each had a different perspective and different interests which meant that we all learnt little bits and pieces from each other."

Mike's language knowledge and communication skills improved greatly within the year. The greatest assistance was his group members, from and with whom he could learn, which was evidenced by his diary entries being almost exclusively about his group members. He improved his language and culture ability, and group work and workmanagement skills through the video project. Interestingly, however, the group members' different perspectives and different interests, and the Japanese students' comments did not influence the compass of his higher-order learning. 


\subsection{Rob (local-mono)}

Rob struggled initially to keep up with the rest of the class due to his absence through an illness. His first group had an unwilling student, and this affected the dynamic of the whole group to the point that another member became totally fed up with this slack student. Despite this unfortunate situation, Rob was determined to do well. Rob consulted with the teacher to discuss what he could do to improve his Japanese. After the discussion, he started to notice the links between the classroom activities and the video creation.

Rob 'did research in order to answer properly' the questions asked by the Japanese students, and wrote his scripts "using the vocabulary and grammar learnt from the readings". He also utilised a community (called Lang8, online language exchange site) outside of the designed community to improve his scripts. He remarked, "I am able to not only get my speech corrected in exchange for helping others with their work, but I am also gaining a better understanding through the comments they give me on where I am going wrong and how to improve. He remarked that "video was instrumental for improving Japanese. I feel that my Japanese has improved a lot".

In semester 2, he formed a group with two students both having a near-native level of Japanese competence. Rob confessed, "To be honest, I feel a bit intimidated working with two extremely fluent members!". However, this challenge motivated him to improve. He remarked, "Not only were they both very supportive and helpful, but it also forced me to want to do better, and I believe that my Japanese improved with each video, as I received very helpful feedback from the Japanese students and the teachers". Rob benefitted from these two group members, not only for his language improvement, but also for his intercultural understanding, as described as follows:

\footnotetext{
"With each of us having spent different amounts of time in Australia, we can all offer a diverse range of views when comparing Japanese and Australian cultures [...] It also made me appreciate Australian culture. I think we would have a lot to gain from adopting Japanese style language and speech in our culture and I believe it would improve Australian culture."
}

Rob did not have the great fortune of having group members with whom he could learn together. However, with his positive attitude combined with his strong will for learning, he improved his language ability and enhanced his intercultural understanding by utilising all the available support, albeit that understanding might still be rather superficial. Rob also exhibited the capability of self-reflection.

\subsection{Shu (international)}

Shu was a quiet student who preferred to study on her own focusing on improving Japanese grammar. She expressed, "I would like to spend time for studying grammar instead of making videos". However, she also acknowledged the benefits of group learning as, "Asking/answering questions of each other deepened the understanding of the language".

Shu was a responsible student who did not want to be a burden on the other members, which was evidenced in remarks, such as, "I'll try my best not to drag the others down", and "I didn't want to produce something that was not acceptable and disappoint my group members". In the first group, the group members seemed to communicate well in terms 
of deciding on overall contents. However, how to present individual parts was up to each member. In the first video, she read her script straight into the camera without using any props. After seeing one of the members being creative, Shu, in later videos, made her parts entertaining, clearly with the Japanese students as audience in mind, as shown in this example:

\begin{abstract}
"I'm thinking of insert some funny quizzes in my video because I would like to interact with the audience through the video. I believe the quizzes can attract the audience's attention and involve them more. It's essential to send out messages accurately, but it's also important to make it enjoyable."
\end{abstract}

In semester 2, she joined the group that had less freedom. One of the members assumed a leader's role assigning the rest of members' tasks, which seemed to have restricted Shu from exhibiting her creativity. Nevertheless, Shu was not daunted by the change, and shifted her focus to research on Japan and Japanese people. One discovery was statistics showing that, comparing to Chinese students, Japanese students are much less willing to go overseas. Shu interpreted this phenomenon as:

\footnotetext{
"I think this is because Japan has deep-rooted culture and customs, and it may not be easy for Japanese people to get accustomed to other culture and customs, which do not go well with their Japanese spirit. I think this may be the reason that Japanese students are a little reluctant about going out of Japan."
}

Throughout the course, she was exposed to different opinions about Japanese language and society. However, Shu remained unwaveringly pro-Japan, as expressed in this remark, "This video project made me realise how much I love Japan and Japanese. Often I find myself talking to my friends about things I learnt in the Japanese classes and through the video makings".

For the first time, Shu experienced non-teacher-centred, non-grammar-focused language learning, and learnt to learn from and with other people. During the course, she was exposed to various perspectives through the prescribed texts for the class, research articles, discussions with classmates, and comments from Japanese students. There were several occasions where she was surprised by some aspects of Japan. However, Shu maintained her favourable attitude towards Japan, and her belief/standpoint was never challenged by her group members nor the Japanese students.

\title{
4.4 Mei (international)
}

Initially Mei was dormant. Mei confessed, "I was totally lost and confused when I was doing my first video", because prior to this, she had never worked in a group, nor filmed herself. Her first diary was a short list of her activities, with little description of her thoughts; the only comment being, "I was so nervous facing the camera and speaking knowing people would watch this". However, Mei adjusted quickly to the new learning environment.

Mei focused on the language learning, and certainly improved her language skills. Mei always had her Japanese friends check the content and grammar of her scripts before sharing them with her group members. Once the Japanese students commented not only on the content of the video, but also on the language use. To this, Mei expressed her appreciation by writing, "Thank you, Kyoko-san. Thank you for your comments. We'll try to do better in the next video!!". She felt that "this video project contributed to 
improvement of our writing and reading skills, since we needed to prepare our script, reading research articles, reading comments, etc., and improved our speaking skills, too".

The video project also gave her opportunities for reflection. When the topics covered were about migration and discrimination, she related them to her own experience:

\begin{abstract}
"Living in another country is definitely not an easy thing. As for me, when I first came to Australia, even though my English was good enough to communicate, I faced some discriminations. [...]They might see foreigners as invaders who take away their opportunity to work. As migrants, a lot of people try so hard and work so hard so that they could stay in this country. All they try to do is just to have a better life and provide a brighter future for their family. There is nothing wrong about it, but people who have prejudices towards them don't understand that. It's sad."
\end{abstract}

She then learnt more about discrimination by interviewing her group members, and read more research articles to deepen her understanding. While reading, she reflected on her past experience of meeting people with different backgrounds, such as a friend (whose parents are ethnically Chinese but naturalised Japanese) born in Japan, but moved to USA after living in China for a couple of years, and returned to Japan for university. The varied cultural differences among the members of her group also made Mei become interested in identity. The group decided to make a video on identity, and posed some questions to the Japanese students regarding this issue. An incoming comment concerned young Japanese people's inner conflict between conformity (following the majority) and individuality (being different). After reading this comment, Mei commented, "people conform in order to not be judged/disliked, however since the prejudice exists all the time disregarding whatever you do to make it disappear, I'll say why care what others think? [...] After all, it's your life and you only live once, YOLO!".

Mei then further investigated conformity, as evidenced in this remark:

\begin{abstract}
"As a collectivist society like many of other Asian countries, Japanese people tend to avoid behaving in a way which make them different from others. Being different often brings them hatred from other people. Therefore, some people change their behaviour, views and attitudes in response to the real or imagined presence of others. In psychology, Solomon Asch and Muzafer Sherif shed light on the determinants of conformity. According to their research $[\ldots]$. ."
\end{abstract}

Neither group work nor film making was familiar to Mei. However, Mei adjusted to the new learning environment, and improved not only her language and culture knowledge and skills, but also research skills. Moreover, the video project gave her opportunities to reflect on her past experience and to view issues with critical eyes.

\title{
4.5 Joy (local-multi)
}

Joy liked the approach of working separately and compiling together at the end. Throughout the year, this preference never changed. Her first and second groups spent little time planning prior to task allocation. After a brief discussion, the members worked independently until a final product was compiled and uploaded on YouTube by one of the members.

Joy felt that she had to "take a more assertive role of dividing up the roles because John and Kate are a little bit passive when it comes to delegating tasks". Joy remarked, "I think that's good because it reduces conflict within the group, which allows us to use our group time together more effectively". At the same time, she was willing to do more than 
others if necessary, as shown in this remark, "I also decided that since no one was delegated the task of giving an introduction to the video, I would record a short introduction as well". Joy was pleased with how her group worked, as expressed as follows:

"I really enjoy the way our group functions. We always try to divide the jobs up so that everyone does the same amount. [...] we seem to get things done extremely efficiently, and don't need to rush it towards the end, so we end up getting a better result!"

Joy learnt a great deal of language and culture, as she remarked, "Our videos have really proven to be a great way to help us memorise and learn how to use the assigned vocab and grammar!". Joy particularly liked the research component of the video project because it made her think about issues, as shown in this remark:

"When the teacher told me about the video project, I thought I wouldn't like doing such a thing, but I now think it is actually good because we can explore our interests by doing mini-research. It made me think things that I'd never thought about. [...] I think it develops our understanding of the Japanese language and culture overall."

Through this project work, Joy improved her project management skills. She displayed leadership, and managed to bring the project to completion effectively while making sure members worked equally. She also improved her language skills and gained knowledge pertaining to globalisation issues affecting Japan and other countries. However, it appears that she, personally, did not benefit from having members with different backgrounds nor from the Japanese students.

\subsection{Lisa (local-multi)}

Lisa did not stand out in class because she was not confident enough to demonstrate her Japanese in front of her classmates. Her personality blossomed in the videos. From the very first video, in which most students were shy, she managed to present herself as bubbly and engaging. She knew that filming and editing videos would take time, and that "a normal oral presentation would definitely be easier". However, she had a positive attitude towards video making from the start, as shown in this statement, "I like having a bit of a change. [...] It's not often that you get the chance to really show yourself in an oral, but because this is a video, it's very open ended and I can try several things". For Lisa, the videos served as a catalyst for discoveries of the self and the other. Towards the end of the year, Lisa remarked, "These videos really make me think about both Japanese culture, and about myself and the world I live in".

Lisa was inherently curious about everything. Because she was full of curiosity, Lisa conducted extensive research and also interviewed people around her, and therefore, had much to tell the Japanese students: "I found it difficult to contain all of my thoughts, opinions and findings from the research into three minutes. There is always so much to say! But I really find all this so interesting, and I want to tell my Japanese friends what I've found and I've thought about'.

When the topic was discrimination against minorities in Japan, she learnt that a member of her group was once bullied at school when he just arrived in Australia, at which she was astonished: 
"I can't believe that this would've happened. In Japan, it may be understandable because most people who live there have the same heritage. But in Australia, everyone comes from all over the place and there are so many people I know who aren't fluent in English, or they have a very heavy accent. $[. .$.$] I suppose we try not to think badly of our own countries."$

She then reflected on others, as follows:

"I've started to think more about what it must be like for those coming to live in other countries from overseas, and how they might be treated. And also challenges that they face. I work a lot with children who have moved to Melbourne from other countries in my volunteer group, so I'm glad that I can now open my eyes more to their situation."

Growing up in a family of different ethnicities provided a great opportunity to learn to accept differences, as shown in this remark, "I've been brought up not to judge other people, and of course in practice, not judging at all is extremely hard, but I don't discriminate at least".

The video project acted as a catalyst to pique Lisa's curiosity. It made her excited about finding things of interest by investigating more widely and deeply. Writing diaries helped her reflect on languages, cultures, and herself and other people. Lisa improved her knowledge, awareness and skills regarding languages, cultures, intercultural relations, reflection on her and others, which are essential factors for intercultural competence.

\section{Discussion}

In the collaborative blended intercultural learning environment of the Japanese language course, all the six students, in theory, should have experienced a similar amount of social and teaching presences. Nevertheless, there were considerable differences in their learning experiences. Presented in this paper are a small number of samples and the data offered only limited insight into students' learning expressed through their diaries and self-evaluation surveys (complemented by the teacher's observation notes). These carefully selected samples, however, should represent various learning experiences, and their data demonstrated that their learning, particularly higher-order learning, experiences were considerably different although they all expressed satisfaction towards the intercultural learning experience. There was a tendency that students with richer multicultural experience exercised higher-order thinking, and constructed and confirmed meaning through discourse and reflection, more than did those with less experience. Lisa and Mei both utilised higher-order thinking skills at the time of the interaction with text and people around them, and at the time of post-discourse reflection. As can be seen in the cases of these students, when learners are exposed to intellectually stimulating resources (text/people), apparently, they can reflect, relate, interpret, analyse, and evaluate, if they have had abundant intercultural experiences. Without having something to relate to and reflect on, learning at the higher-order level may be limited. For example, Mike seemed to be fortunate to have an ideal learning environment with intellectual subject matters and supportive people with different cultural backgrounds. However, his reflection did not go beyond language learning. Rob did show an improvement in intercultural understanding, but only to a small degree. 
The data revealed that the student's mindset towards learning also plays an important role. Lisa and Rob showed positive attitudes towards the video project, and were willing to learn from people around them. Mei was flexible and adaptable to the unfamiliar learning environment, with which she was uncomfortable in the beginning. However, in the case of Joy, since she was focused on completing the task, she let opportunities for intercultural learning from others pass by. Research suggests that learner experience of interaction is positive when there is a mutual goal to be achieved (Deardorff, 2011; Laal and Laal, 2012). However, it appears that, when the focus is too much on the achievement of the goal, the process could be neglected, and learning could be sacrificed. Shu's case is interesting. Throughout the year, she worked diligently and completed her tasks effectively, unaffected by others. Laal and Laal (2012, p.491) claim that "in a collaborative learning environment, learners are challenged both socially and emotionally as they listen to different perspectives". Shu, however, did not benefit greatly from the intercultural learning opportunities. She had a fixed mindset towards learning, and she performed excellently within the boundaries of her way of learning.

Students, who are used to traditional teacher-centred learning, were sensitive to what was required. Although the real intention of the video collaborative project was to enhance higher-order thinking, the perceived goal was creating videos. Perhaps, this made some students focus exclusively on task completion. It is clear that teaching presence needs to be promoted more to be accurately perceived by learners, as it affects learners' cognitive presence. Perceived teaching presence also potentially influences how learners exercise social interaction. The data of the current study revealed that students' communication often focused on how to complete the tasks, and not so much on sharing experiences, thoughts and opinions. Once having understood teachers' intention, learners may autonomously interact actively with members of their community in order to improve their higher-order thinking skills.

There may be two ways to promote teaching intention. One is to provide learners with interactive orientations on intercultural learning several times during a course. In the current study, such orientation was given at the start of the course, and the aim and objectives were posted on an online subject site. Nevertheless, as Rod understood only after an individual consultation, some learners may not fully understand teachers' intention from one session of orientation. For intercultural learning to succeed, "there must be willingness, a conscious attempt, and a desire to achieve intercultural competence" [Gopal, (2011), p.374] in learners.

Another is to modify assessment. Instead of simply assessing artefacts (e.g., videos), it is vital to implement regular formative assessments of social presence (Gruba and Clark, 2013), such as how much contribution a learner made towards group learning, and how a learner reached out to learn from others. For improving cognitive presence through teaching presence, learners should be assessed on their reflection ability (Scarino, 2009). The question arises whether learners can improve higher-order thinking skills without having much previous intercultural experience, on which to reflect. Intercultural learning environment at universities should enhance such skills, not only of those who are already capable students, but also of those who have not had many intercultural opportunities, by giving them opportunities to hear other students' experiences. Indeed 'active listening' is claimed to be an important intercultural skill (Lee et al., 2012). Thus a multimethod, multiperspective assessment plan is required (Deardorff, 2011). Assessment for intercultural learning at a university should involve examinations that cover a wide range 
of communicative performance and reflection (Liddicoat et al., 2009), and it should be clearly stated in a course outline for students to appreciate what is expected of them, and be repeatedly reminded. How to implement and actually manage to conduct such time-consuming assessment, however, may pose challenges to mainstream tertiary educators, who already have heavy workloads.

Research suggests that there are strong correlations between perceived social presence and learner satisfaction and perceived learning (Richardson and Swan, 2003; Swan et al., 2009). In the current study, the majority of students evaluated highly for social presence, and expressed satisfaction towards the course, and mentioned that they had learnt much. However, the findings from the in-depth examination indicated that quality of social presence, the level of satisfaction and the constructs of perceived learning may all vary from student to student. Some students did not utilise social presence for higher-order learning.

The use of video in collaborative blended learning certainly promoted social presence. Since there was more freedom for creativity to emerge in videos, compared to classroom presentations or essays, videos saw lively interactions among members (e.g., role-play, TV show, news, panel discussion, interview), and effective audio-visual aids (e.g., object, picture, map, graph, sub-title, caption, coloured texts, sound effect, music). Not only group members who created videos, but students in Japan appreciated the audio-visual capacity of video. Some comments included positive words such as engaging, grabbing, fun, easy to understand and effective.

However, international interaction using the social networking function of YouTube was not as active as expected, and the interaction did not improve much even after we switched to Facebook (with links to YouTube videos). Although the research findings that YouTube users see YouTube as a platform for interaction rather than a mere broadcasting application (Rotman and Preece, 2010), in the current study, interaction was confined to the results of teachers' direct instructions, except for a few students. For autonomous interaction to occur, it is essential that learners have a certain level of higher-order thinking skills to be able to perceive teaching presence and fully understand the benefits of social presence. Perhaps, it is also crucial that social interaction partners have a certain level of higher-order thinking skills so that they bring academically stimulating discourse.

Using CoI, this paper examined the exercise of higher-order thinking (cognitive presence) in six students with different cultural backgrounds, who engaged in intercultural learning activities in a collaborative blended learning environment using video sharing, within a university foreign language course. It was hypothesised that multicultural experience would enhance cognitive presence, as profound life experience could fuel higher-order thinking. However, the results of an in-depth analysis of diaries kept by the six students and other supplemental data showed that while prior intercultural experience of individual students plays a key role, both teaching presence and social presence also affect the exercise of higher-order thinking. The findings suggest that perceiving teaching presence correctly and utilising social presence will lead to exercising higher-order thinking, and consequently perceive great cognitive presence. However, for this scenario to work, teachers, collaborators, and the learner her/himself are perhaps required to have a certain level of experience, knowledge and higher-order thinking skills. As Xin (2012) claims, the three components of CoI are interwoven, and therefore should not be analysed as separate and distinct aspects of learning. This study 
revealed the relationship of the three presences through the presences explicitly and implicitly expressed in the students' data, which are artefacts of inherently cognitive/meta-cognitive activity. Much more research investigating individual experiences of the teaching, social and cognitive presences, in various formats, is needed for finding the individual differences of the intertwined relationship of the three presences.

\section{Acknowledgements}

This project is funded by The University of Melbourne Asia Institute e-learning grant.

I would like to thank all who participated in this project for their contribution: my students for sharing their views with me, and the students in Japan for assisting this project. Special thanks go to my international collaborator of this project, Professor Richard Harrison for valuable suggestions that assisted in realising this project.

\section{References}

Artello, K. (2014) 'What they leaned: using multimedia to engage undergraduates in research', Innovative Higher Education, Vol. 39, pp.169-179.

Burke, S.C. and Snyder, S.L. (2008) 'YouTube: an innovative learning resource for college health education courses', International Electronic Journal of Health Education, Vol. 11, pp.39-46.

Byram, M. (2008) From Foreign Language Education to Education for Intercultural Citizenship. Essays and Reflections, Multilingual Matter, Philadelphia.

Casner-Lotto, J. (2006) Are They Really Ready to Work?: Employers' Perspectives on the Basic Knowledge and Applied Skills of New Entrants to the 21st Century U.S. Workforce, Conference Board, New York [online] http://www.p21.org/storage/documents/ FINAL_REPORT_PDF09-29-06.pdf (accessed 10 October 2014).

Crozet, C., Liddicoat, A.J. and Lo Bianco, J. (1999) 'Intercultural competence: from language policy to language education', in Lo Bianco, J., Liddicoat, A.J. and Crozet, C. (Eds.): Striving for the Third Place: Intercultural Competence through Language Education, pp.1-22, Language Australia, Canberra.

Daspit, J.J. and D'souza, D.E. (2012) 'Using the community of inquiry framework to introduce Wiki environments in blended learning pedagogies: evidence from a business capstone course', Academy of Management Learning and Education, Vol. 11, No. 4, pp.666-683.

Deardorff, D.K. (2006) 'Identification and assessment of intercultural competence as a student outcome of internationalization', Journal of Studies in International Education, Vol. 10, No. 3, pp.241-266.

Deardorff, D.K. (2011) 'Assessing intercultural competence', New Directions for Institutional Research, No. 149, pp.65-79, DOI: 10.1002/ir.381.

Garrison, D.R., Anderson, T. and Archer, W. (2000) 'Critical inquiry in a text-based environment: computer conferencing in higher education', The Internet and Higher Education, Vol. 2, Nos. $2-3$, pp. $87-105$.

Garrison, D.R. and Kanuka, H. (2004) 'Blended learning: uncovering its transformative potential in higher education', The Internet and Higher Education, Vol. 7, No. 2, pp.95-105, DOI: $10.1016 / j$.iheduc.2004.02.001. 
Garrison, D.R. and Vaughan, N.D. (2008) Blended Learning in Higher Education: Framework, Principles and Guidelines, Jossey-Bass, San Francisco, CA.

Gopal, A. (2011) 'Internationalization of higher education: preparing faculty to teach cross-culturally', International Journal of Teaching and Learning in Higher Education, Vol. 23, No. 3, pp.373-381.

Gruba, P. and Clark, C. (2013) 'Formative assessment within social network sites for language learning', in Lamy, M.N. and Zourou, K. (Eds.): Social Networking for Language Education, Palgrave Macmilan, New York.

Guzzo, T., Grifoni, P. and Ferri, F. (2012) 'Social aspects and Web 2.0 challenges in blended learning', In Anastasiades, P.S. (Ed.): Blended Learning Environments for Adults: Evaluations and Frameworks, pp.1-340, IGI Global, Hershey, PA, DOI:10.4018/978-1-4666-0939-6.

Hinkelman, D. and Gruba, P. (2012) 'Power within blended language learning programs in Japan', Language Learning and Technology, Vol. 16, No. 2, pp.46-64.

Laal, M. and Laal, M. (2012) 'Collaborative learning: what is it?', Procedia-Social and Behavioral Science, No. 31, pp.491-495.

Lee, A., Poch, R., Shaw, M. and Williams, R. (2012) 'Emerging diversity in undergraduate classrooms: a pedagogy for developing intercultural competence', ASHE Higher Education Report, Vol. 38, No. 2, pp.1-107, Wiley Periodicals, San Francisco.

Liddicoat, A.J., Papademetre, L., Scarino, A. and Kohler, M. (2003) Report on Intercultural Language Learning, Australian Government, Department of Education, Science and Training, Melbourne.

Lincoln, Y.S. and Guba, E.G. (1985) Naturalistic Inquiry, Sage, Beverly Hills, CA.

Richardson, J.C. and Swan, K. (2003) 'Examining social presence in online courses in relation to students' perceived learning and satisfaction', Journal of Asynchronous Learning Networks, Vol. 7, No. 1, pp.68-88.

Rotman, D. and Preece, J. (2010) 'The 'WeTube' in YouTube - creating an online community through video sharing', International Journal of Web Based Communities, Vol. 6, No. 3, pp.317-333.

Scarino, A. (2009) 'Assessing intercultural capability in learning languages: some issues and considerations', Language Teaching, Vol. 41, No. 1, pp.67-80.

Sheets, R.H. (2009) 'What is diversity pedagogy?', Multicultural Education, Vol. 16, No. 3, pp.11-17.

Swan, K., Garrison, D.R. and Richardson, J.C. (2009) 'A constructivist approach to online learning: the community of inquiry framework', in Payne, C.R. (Ed.): Information Technology and Constructivism in Higher Education: Progressive Learning Frameworks, pp.43-57, ICI Global, Hershey, PA.

Toyoda, E. and Chia, K. (2013) 'Turning a disparate Asian language classroom into an intercultural learning environment', Electronic Journal of Foreign Language Teaching, Vol. 10, No. 2, pp.154-175.

Vygotsky, L.S. (1978) Mind in Society: The Development of Higher Psychological Processes, Harvard University Press, Cambridge.

Xin, C. (2012) 'A critique of community of inquiry framework', International Journal of E-Learning and Distance Education, Vol. 26, No. 1 [online] http://www.ijede.ca/index.php/ jde/article/view/755/1333 (accessed 15 November 2014).

Zhang, H. (2012) 'Collaborative learning as a pedagogical tool to develop intercultural competence in a multicultural class', China Media Research, Vol. 8, No. 2, pp.107-111. 


\section{University Library}

\section{- M I I N E R VA \\ A gateway to Melbourne's research publications}

Minerva Access is the Institutional Repository of The University of Melbourne

Author/s:

Toyoda, E

Title:

Collaborative video blended learning for exercising higher-order thinking - evaluation using community of inquiry framework

Date:

2015

\section{Citation:}

Toyoda, E. (2015). Collaborative video blended learning for exercising higher-order thinking - evaluation using community of inquiry framework. International Journal of Social Media and Interactive Learning Environments, 3 (2), pp.126-126. https://doi.org/10.1504/ ijsmile.2015.070763.

Persistent Link:

http://hdl.handle.net/11343/58378 